\title{
DESAFÍOS PARA EL DESARROLLO DE UNA COMPETENCIA MULTIMODAL DISCIPLINAR. EL CASO DEL GÉNERO INFORME DE POLÍTICA MONETARIA (IPOM) ${ }^{1}$
}

\author{
CHALLENGES FOR THE DEVELOPMENT OF A DISCIPLINARY \\ MULTIMODAL COMPETENCE. THE GENRE MONETARY POLICY \\ REPORT CASE (MPR)
}

\author{
Liliana VÁSQUEZ-ROCCA \\ Pontificia Universidad Católica de Valparaíso, Chile \\ 1_rocca@hotmail.com
}

Resumen: El estudio de los sistemas semióticos que convergen en la construcción del significado del texto, ha tenido predominio en los últimos 30 años y ha implicado un abandono del logocentrista, derivando en desafíos para investigadores y para quienes leen textos. Por ejemplo, estudiantes universitarios se ven enfrentados a géneros multimodales claves en su tránsito al mundo profesional. Por tanto, esta investigación busca describir el género IPOM en el cual la configuración multisemiótica es una propiedad relevante. Los hallazgos muestran que leer textos del género IPOM requiere una competencia multimodal que va más allá de comprender sólo el sistema verbal.

Palabras clave: Compentencia multimodal. IPOM. Multimodalidad. Sistemas semióticos. 
Abstract: The study of semiotics sistems that converge in the construction of the meaning of a text, has been predominant in the last 30 years and has implied an abandonment of the logocentrist, resulting in new challenges for researchers and for those who finally read the texts. For example, university students are confronted to multimodal genres that are the key to their transition to the professional world. Therefore, the following research seeks to describe the MPR genre in wich the multisemiotic configuration is a relevant property. The findings shows that reading texts of the MPR genre requires the development of a multimodal competence that goes beyond comprehend only the verbal sistem.

Key Words: Multimodal competence. MPR. Multimodality. Semiotics systems.

\section{INTRODUCCIÓN}

En los últimos 30 años se ha producido un giro multimodal en el estudio del texto, ya que no sólo se consideran las palabras como constitutivas de significados, sino que se analizan también otros elementos que contribuyen a la construcción del sentido comunicativo. Sin embargo, esta visión no es una preocupación teórica reciente, por el contrario, fue presentada por Saussure (1969) y Benveniste (1999) en los comienzos de la lingïuística como ciencia. Estos autores clásicos proponen que existen otros sistemas semióticos que contribuyen al significado además del verbal. No obstante lo anterior, el enfoque multimodal tomó fuerza desde la propuesta de Halliday (1982) sobre la construcción de significados del ser humano a partir de la confluencia de diversos sistemas semióticos. Posteriormente, Kress y van Leeuwen (1996) elaboran la teoría de la gramática visual que tuvo una importante repercusión en este emergente ámbito de estudio. Esta nueva perspectiva ha implicado un abandono de la visión logocentrista en el estudio del texto (Parodi, 2015) que marcó durante largas décadas la investigación en lingüística y ha derivado en nuevos desafíos para los investigadores. Así, en el 2016 se cuenta con un desarrollo considerable de estudios multimodales en todo el mundo, que buscan avanzar en explicar cómo finalmente se construye el significado en un texto.

Ahora bien, la multimodalidad no sólo es un desafío para quienes 
están realizando estas investigaciones, sino también para aquellos que leen, pues se trata de textos complejos, del que no sólo se debe elaborar una representación mental del significado a partir, exclusivamente, del sistema verbal, sino de la confluencia de múltiples sistemas (matemáticos, gráfico visual, entre otros). Si bien los programas de estudio de enseñanza básica y media en Chile han comenzado a considerar la formación multimodal, por ejemplo, en los textos de estudio, ello aún resulta incipiente, principalmente, porque es escasa la investigación de textos con enfoque multimodal en Chile. Como consecuencia, los estudiantes cuando ingresan a la educación universitaria, no siempre presentan una competencia multimodal en su área de estudio específica, a pesar de que en su tránsito, desde el mundo académico al profesional, los textos que leen son esencialmente multimodales.

En el marco de lo expuesto precedentemente, esta investigación busca describir multidimensionalmente el género Informe de Política Monetaria (IPOM), que pertenece al discurso profesional de la economía, pero que estudiantes del área también leen durante su formación, por tanto, se trata de un género importado (Bolívar \& Parodi, 2015; Parodi, 2015). Para lograr este objetivo, se ha optado por una metodología que integra distintas técnicas y análisis, dividida en 2 dimensiones, esto es: "artefactos multisemióticos" y "relaciones intersemióticas". Estas categorías abordan el desafío de un análisis multimodal y en conjunto permiten realizar una descripción pormenorizada del género que no se podría efectuar aislando cada dimensión. Tras el análisis, los hallazgos integradamente muestran que leer textos del género IPOM requiere del desarrollo de una competencia multimodal propia de la disciplina económica y que va más allá de comprender sólo el sistema verbal, sino que incluye otros sistemas semióticos, puesto que un estudiante universitario del área, debe integrar el sistema verbal y la lectura de gráficos de modo coherente si quiere lograr comprender ese texto en particular.

Para el desarrollo del artículo, el escrito está dividido en cuatro partes. En primer lugar, se realiza una contextualización teórica de la noción de multimodalidad, sistemas semióticos y artefactos multisemióticos, luego, se abordan las relaciones intersemióticas y el género IPOM. A continuación, se define la metodología y, posteriormente, se presentan los resultados y discusión del análisis. Finalmente, se exponen las conclusiones de esta investigación. 


\section{MULTIMODALIDAD, SISTEMAS SEMIÓTICOS Y ARTEFACTOS MULTISEMIÓTICOS}

El estudio de cómo los seres humanos construyen significados de diversas formas para comunicarse con el entorno no es exclusivo de los investigadores de la multimodalidad, ni de la lingüística, sino que ha sido propuesto desde diversos ámbitos. Ahora bien, en específico en la lingüística, el logocentrismo imperante en la disciplina opacó durante varias décadas el estudio desde una perspectiva multimodal (Parodi, 2015) aun cuando lingüistas fundacionales contemplaron siempre otros sistemas además del verbal (Saussure, 1969; Benveniste, [1977] 1999; Halliday, 1982), pero otorgando siempre un rol central al sistema verbal.

En cuanto a su inicio, Kaltenbacher (2007) ha situado el origen del estudio multimodal en los clasicistas alemanes, sin embargo, una nueva revisión de la temática sitúa el origen en un periodo histórico anterior, esto es, en la Grecia antigua, en particular, en el texto Poética de Aristóteles ([1946] 2003). En la Poética el autor realiza una explicación de los constituyentes cualitativos de la tragedia dividida en dos ámbitos, uno textual y otro de la representación teatral. En el nivel textual el autor lo divide en: fábula, pensamiento, personajes y dicción; y en el segundo, melodía y espectáculo. En este análisis, Aristóteles ([1948] 2003) plantea la dualidad semiótica del discurso teatral como discurso complejo, entendido como el conjunto de componentes textuales y su representación formado por signos verbales y por signos no verbales (Albaladejo, 2012). Por tanto, el inicio de los estudios de la multimodalidad es propuesto seminalmente por Aristóteles ([1948] 2003) a partir de su estudio de la tragedia griega. No obstante lo anterior, es necesario reconocer que los estudios multimodales tomaron preponderancia, a partir de las ideas de Halliday (1982) quien propuso que el lenguaje es parte del sistema social y el más importante en la construcción de significados, pero que no es el único. Posteriormente, Kress y van Leeuwen (1996) desarrollaron los fundamentos de la investigación multimodal a partir de tres escuelas: Praga, Paris y Australia. Desde su perspectiva, se cuestiona la idea que representar algo sea equivalente a ponerlo en un código en particular, sino que más bien, se relaciona con diseñar de manera deliberada la creación de significado (meaning making) con diferentes elementos. En otras palabras, 
si la construcción del significado del texto está conformado por diversos sistemas semióticos que confluyen para otorgan la coherencia global del discurso, avanzar en la explicación implica acercarse a entender si el procesamiento se hace separando o integrando los diversos sistemas semióticos que están involucrados en un texto.

Desde Kress y van Leeuwen (1996) en adelante, el desarrollo del estudio de la multimodalidad se amplió de manera diversa y con límites difusos, lo que ha arrojado como resultado una gran cantidad de conceptualizaciones para nociones que, en ocasiones, convergen en ideas similares. A pesar de las divergencias teóricas y terminológicas, los estudios empíricos sobre multimodalidad han aumentado considerablemente en todo el mundo (e.g. Schnotz, 2005; Hiippala, 2012; Taboada \& Habel, 2013; Candlin, 2014; Bateman, 2014; Jewitt, Bezerman \& O’Halloran, 2016). En particular, Jewitt (2009) propone dividir la investigación en multimodalidad a partir de 3 visiones: semiótico social, interaccional y discursivo. En el caso del enfoque semiótico social, se enfatiza en mayor grado el instante de la construcción de significado en un contexto y con determinados recursos, lo que se puede graficar, por ejemplo, con la propuesta de Schnotz (2005) y su modelo de aprendizaje multimodal integrado. En cambio, el análisis interaccional pone su atención en el momento de la creación de significado y los actores involucrados; mientras que el análisis del discurso multimodal pone su foco de atención en el sistema (Norris, 2014), en las elecciones que se toman y los principios de organización en un determinado contexto (e.g. Stöckl, 2004; Matthiessen, 2009; Parodi \& Julio, 2015). Posteriormente, Jewitt et al. (2016) distinguen dos tipos de estudios en multimodalidad. En primer lugar, los que diseñan su investigación incluyendo como punto central la multimodalidad y, por tanto, se incluye en la teoría, en las preguntas de investigación y en el método; $\mathrm{y}$, en segundo lugar, otros estudios que adoptan conceptos multimodales, pero que no están en el centro de la investigación. Cabe señalar que este escenario planteado del estudio multimodal no es concluyente, pues dependerá también de la disciplina desde la cual se aproxime el investigador, pero sí permite orientar a nuevos científicos en un ámbito de estudio en franco desarrollo.

En particular, respecto de la perspectiva de análisis de discurso multimodal, al que se acoge esta investigación, Stöckl (2004) propone observar la multimodalidad a partir de la idea de sistema semiótico que se constituye en un repertorio de signos, en los que el ser humano puede 
seleccionar, entre las opciones que entrega cada sistema, los signos que son pertinentes para lograr el propósito comunicativo en contextos sociales variados. Las elecciones no son al azar, sino que se estructuran a partir de un conjunto de reglas que establecen la manera en que estos signos deben combinarse para construir significado a través de los géneros discursivos. Al respecto, Lemke (1998) sostiene que no es posible construir significado a través de un solo sistema semiótico. Por su parte, Matthiessen (2009), agrega que estos sistemas multisemióticos funcionan en paralelo en la construcción y en el transporte de significado. Todo lo anterior resulta fundamental como cimiento para entender este enfoque de estudio.

\subsection{Sistemas semióticos y artefactos multisemióticos}

Los sistemas semióticos, en esencia, son un conjunto de signos arbitrarios que se han creado con el paso del tiempo y que se comparten en una comunidad, la que asigna valores diferentes a cada uno de esos signos (Saussure, 1969; Benveniste, [1977] 1999). Éstos tienen sus propias formas de constituirse y de construir significado, los que se han desarrollado de manera progresiva y permiten elaborar discursos complejos y coherentes a través de diversos géneros (Matthiessen, 2009).

En este sentido, Benveniste ([1977] 1999) propone cuatro características que permiten identificarlos, definirlos y establecer las relaciones entre sistemas. Al respecto señala que un sistema semiótico está constituido por un modo de operación, un dominio de validez, un tipo de naturaleza y número de signos y un tipo de funcionamiento (Benveniste, [1977] 1999). En cuanto a las relaciones intersistemas, Benveniste ([1977] 1999) propone tres que se pueden producir entre sistemas: de engendramiento, de homología y de interpretación. En las relaciones de engendramiento, un sistema puede engendrar a otro, por ejemplo, el sistema verbal habría engendrado el sistema lógico-matemático. En segundo lugar, en cuanto a la relación de homología, quiere decir que se podría establecer una correlación entre las partes de dos sistemas semióticos, pero que esta vinculación se produce entre sistemas distintos, por ejemplo, establecer un paralelismo entre la arquitectura gótica y el pensamiento escolástico. Por último, la relación de interpretación quiere decir que un sistema semiótico puede interpretar a otro sistema. Esto último es fundamental, ya que el autor propone y justifica desde esa relación, el principio que la lengua es el 
interpretante de todos los otros sistemas semióticos.

Ningún sistema dispone de una lengua en la que pueda categorizarse e interpretarse según sus distinciones semióticas, mientras que la lengua puede, en principio, categorizar e interpretar todo, incluso ella misma (Benveniste, [1977] 1999: 65).

En este sentido, para el autor el sistema verbal, la lengua, es el único con la capacidad de interpretar a otros y, por tanto, ocupa un lugar primordial en el universo de los sistemas de signos. Así, en esta investigación los sistemas semióticos se conciben como un conjunto de signos que tienen un modo de operación, un dominio de validez y funcionamiento y que su combinación sinérgica permite la construcción de significados (trabajo semiótico) coherentes.

Por su parte, un artefacto multisemiótico, se produce al combinar diferentes sistemas semióticos. Desde el ámbito de la lingüística, la noción de artefacto no ha sido suficientemente explorada aún. Uno de los investigadores que avanza en esta línea es Parodi (2010, 2015) al definir los artefactos multisemióticos como aquellos elementos creados por la confluencia de múltiples sistemas semióticos y que tienen un rol importante en la construcción del significado global de un texto. Parodi (2010, 2015) propone clasificar a los artefactos bajo tres criterios: función, modalidad y composición. Estos criterios han sido aplicados, además, en otras investigaciones (Parodi, 2015; Boudon \& Parodi, 2014) en textos que circulan en el contexto académico. En el caso del ámbito de la economía, se cuenta con investigaciones que describen los tipos de artefactos multisemióticos en el género Manual (Boudon \& Parodi, 2014).

Tanto sistemas semióticos como artefactos multisemióticos tienen características que comparten, pero también dimensiones que los diferencian. Ambos están supeditados a las elecciones que hace el sujeto que produce los textos escritos de acuerdo con ciertos propósitos comunicativos. Develar cuáles son estos propósitos es lo que motiva a realizar un estudio descriptivo multimodal del género IPOM. 


\section{RELACIONES INTERSEMIÓTICAS}

Es precisamente la confluencia de múltiples sistemas semióticos $\mathrm{y}$ artefactos multisemióticos lo que genera nuevos tipos de relaciones semánticas en el texto: las relaciones intersemióticas. Al respecto, existen dos enfoques en las investigaciones de las relaciones intersemióticas: por un lado, "intrasemiótica" y, por otro, "intersemiótica". En la primera, el foco se centra en comprender y describir las relaciones que se establecen en cada uno de los sistemas que participan en la creación de significado de un texto, pero de manera aislada, es decir, cada sistema independientemente; mientras que en la segunda, la mirada emerge a partir de las relaciones entre sistemas y jerarquías generados a partir de la utilización de estos en un texto. Precisamente, esta investigación busca avanzar en el estudio entre sistemas semióticos, en particular, entre el sistema verbal y un artefacto multisemiótico, ámbito de investigación que ha sido abordado desde una mirada centrada en lo descriptivo y otra focalizada en el procesamiento.

En el ámbito descriptivo de las relaciones intersemióticas, una de las principales líneas de investigación se ha desarrollado fundamentalmente en la Lingüística Sistémica Funcional (LSF). Por ejemplo, Royce (1999) estudia la co-ocurrencia de las relaciones entre un artefacto y el sistema verbal, utilizando un corpus extraído de la revista The Economist. El investigador, realiza un análisis de las relaciones semánticas, considerando las metafunciones ideacional, interpersonal y textual de la imagen y el sistema verbal en economía. En su estudio el autor propone el concepto de complementariedad intersemiótica, el que se entiende como la forma en que un artefacto se complementa con el sistema verbal para construir un significado global. Así el autor sostiene que un texto contextualizado y coherente utiliza distintos sistemas semióticos que se complementan para elaborar significado. También, siguiendo la línea de la LSF, Liu y O'Halloran (2009) plantean un estudio de la "textura intersemiótica" como la propiedad fundamental de la coherencia de los textos multimodales, proponiendo una serie de mecanismos de cohesión entre el sistema verbal y un artefacto en su estudio.

Sumado a lo anterior, Martinec y Salway (2005) presentan una propuesta de análisis de las relaciones entre imagen y sistemas verbal que se basó en los planteamientos de Barthes (1977) y las relaciones lógicosemánticas de la LSF (Halliday, 1982). Los géneros analizados fueron las 
enciclopedias electrónicas, los avisos publicitarios, los textos escolares de anatomía y marketing. Los resultados de la investigación de Martinec y Salway (2005) arrojaron que el artefacto imagen y el sistema verbal tienen diferentes estatus si es que uno modifica al otro, lo que genera una dependencia del artefacto al sistema verbal o viceversa (Barthes, 1977, 2014). Mientras que existen casos en que el artefacto y el sistema verbal poseen un estatus similar, los dos aportan información al mismo nivel, lo que se considera una relación de complementariedad. Por otro lado, en cuanto a los resultados vinculados a las relaciones lógico-semánticas entre artefacto y sistema verbal, Martinec y Salway (2005) señalan que se pueden dar, principalmente, de dos formas: expansión y proyección. Sin embargo, en este estudio no se problematiza la idea del núcleo, ya que siempre se está observando el sistema verbal como central.

Desde la Teoría de la Estructura Retórica (RST, por sus siglas en inglés) propuesta por Mann y Thompson (1988), Taboada y Mann (2006) y Taboada y Habel (2013), se ha propuesto una perspectiva diferente para estudiar las relaciones intersemióticas, ya que además de la visión semántica de la relación se incluye una visión pragmática. En específico, Taboada y Habel (2013) han estudiado las relaciones intersemióticas entre gráficos y tablas y sus cotextos verbales, en una muestra de textos de 3 géneros discursivos diferentes que consideraban 1.500 páginas y alrededor de 600 artefactos. Los autores plantean la existencia de múltiples conexiones entre artefacto y cotexto verbal; sin embargo, Taboada y Habel (2013) no justifican la elección de los artefactos multisemióticos que analizan. En este estudio, es difícil observar si los artefactos que revisan son los más recurrentes en un género específico, o bien, corresponden a elecciones subjetivas de los autores; no obstante, sus aportes resultan esenciales desde una perspectiva teórica, ya que abren una línea de análisis en multimodalidad que permite abordar este fenómeno de una manera diferente de lo que había primado en los estudios en estas materias. Hasta la fecha de esta investigación, la RST ha definido un total de 30 tipos de relaciones divididas en relaciones Multinucleares, de Presentación y de Contenido. De acuerdo a los planteamientos de Mann y Thompson (1988), esta taxonomía no constituye una totalidad cerrada ni menos definitiva, sino que se declara como abierta y, entonces, pueden surgir otros tipos de relaciones semántico-pragmáticas. Precisamente, se ha optado por utilizar la RST en este estudio, ya que proporciona, dentro de las diversas 
investigaciones en multimodalidad, una aproximación contextual, incluyendo el nivel pragmático, que no aportan otras taxonomías.

Ahora bien, en el enfoque del procesamiento se han realizado investigaciones desde la psicología (Paivio, 1979, 1986; Sadoski \& Paivio, 2011; Schnotz, 2002, 2005; Schnotz \& Bannert, 2003) y la psicolingüística (Parodi, 2010; Gladic, 2012; Parodi, 2014; Parodi \& Julio, 2015). Uno de los principales investigadores del procesamiento del texto multimodal desde la psicología es Paivio (1979) quien planteó la teoría del código dual (TDC, por sus siglas en inglés). El autor propone la convergencia de dos códigos representacionales, verbal y no verbal, estarían interconectados y, por tanto, el procesamiento del texto se haría en paralelo. Paivio (1986) construye un modelo explicativo que busca identificar cómo se realiza el procesamiento de ambos códigos, centrándose principalmente en la organización e interconexiones del sistema verbal y la imagen (Sistema no verbal). Posteriormente, Paivio (2007) en un afán por extender su teoría, busca explicar la evolución de la mente, señalando que el paso filogenético del ser humano desde una mente eminentemente verbal hacia otra que procesa diversos tipos de información, está dada por la manera en que el sistema verbal trabaja sinérgicamente con otras formas (sistemas) de codificación. Por su parte, Sadoski y Paivio (2011) buscan distinguir el procesamiento desde el cual proviene el conocimiento del mundo y el lingüístico.

En esta misma línea, Mayer $(2001,2005)$ también desarrolla la teoría cognitiva del aprendizaje multimedial. El autor propone tres principios cognitivos esenciales para comprender cómo se realiza el aprendizaje: un canal dual, capacidad cognitiva limitada y procesamiento activo, es decir, que existe más de un proceso cognitivo coordinado. Respecto del procesamiento multimodal, el autor parte de la idea de que ambos canales se codifican de manera independiente a través de la memoria sensorial y luego en la memoria de trabajo se integran a través de la construcción de un modelo verbal y de la imagen. Así, luego de la integración dicho conocimiento se integra a la memoria a largo plazo. Al igual que Paivio $(1979,1986,2007)$, Mayer $(2001,2005)$ no logra explicar en detalle cómo se procesa la integración de los sistemas y en ello recaen principalmente las críticas a estas teorías expuestas.

Una tercera propuesta en esta perspectiva la presenta Schnotz (2002) que si bien usa como punto de partida a Paivio (1979, 1986), 
se diferencia (de este $\mathrm{u}$ otro) en la manera que interrelaciona las representaciones verbales y del artefacto imagen. Schnotz (2002) propone un modelo integrado de comprensión textual e imágenes que se presentan en diferentes modalidades sensoriales. Al respecto, Schnotz (2002) sostiene que el lector de un texto construye una representación mental de la estructura superficial del texto, generando una representación proposicional del contenido semántico y, finalmente, construye desde ese texto base un modelo mental. El sistema verbal, text en el caso de Schnotz (2002), y las imágenes se basan en diferentes sistemas de signos y emplean principios de representación bastante distintos. El sistema verbal se constituye de representaciones descriptivas, las imágenes, en cambio, son icónicos. Por su parte, Schnotz y Bannert (2003) avanzan al afirmar que las imágenes facilitan el aprendizaje solo si los individuos tienen poco conocimiento previo y si la materia se visualiza de manera acorde a la tarea. No obstante, si los buenos lectores con alto conocimiento previo reciben un texto con imágenes en las que la materia se visualiza de manera inadecuada, entonces esas imágenes pueden interferir con la construcción de un modelo mental apropiado para la tarea. Schnotz (2005) avanza en proponer no sólo un nivel cognitivo, sino también uno perceptual. Este último, surge en el comienzo del proceso de aprendizaje multimodal y se caracteriza porque incluye el canal auditivo y visual que posibilitan el paso de la información textual verbal y visual a la memoria de trabajo.

En resumen, desde la psicología las propuestas de Paivio (1979, 1986, 2007), Mayer (2001, 2005) y Schnotz (2002, 2005), tienen como punto de partida del procesamiento cognitivo la separación entre el sistema verbal y la imagen -artefacto multisemiótico- a partir de lo cual se construye una representación proposicional del texto y una visión gráfica.

Desde la psicolingüística, Parodi (2014) ha propuesto en la teoría de la comunicabilidad (TC) que la comprensión de los textos implica un macroproceso en el que intervienen diferentes factores de tipo psicosociobiolingüístico. En este sentido, Parodi (2010) realiza su estudio a partir de cuatro sistemas semióticos: verbal, matemático, visualgráfico y tipográfico, todos ellos articulados a través de los diversos géneros discursivos, por tanto, su planteamiento propone una vinculación ineludible entre el género y los sistemas semióticos involucrados. Al menos existirían cuatro sistemas semióticos en los textos: verbal, gráfico, matemático y tipográfico. Asimismo, Gladic (2012) exploró el 
procesamiento de la comprensión multimodal en estudiantes de pedagogía en castellano y comunicación a través de dos pruebas de comprensión; una predominantemente verbal y otra con el artefacto mapa. También, Parodi y Julio (2015) han explorado el procesamiento cognitivo multimodal a través de estudios basado en corpus y experimentación. Tras las pruebas, los autores plantean que no hay evidencia que permita establecer una vinculación entre la predominancia de un sistema semiótico y un nivel más alto de comprensión de textos escritos especializado de Economía. No obstante, los estudiantes sí logran leer a partir de un solo sistema predominante ya sea verbal o gráfico.

En definitiva, tanto los estudios de las relaciones intersemióticas desde la descripción como del procesamiento están avanzando poco a poco para comprender mejor el fenómeno de la multimodalidad, principalmente basados en la idea que la representación mental del sujeto es a través de dos códigos diferentes. No obstante lo anterior, aún queda por desarrollar y entender bastante en el ámbito de las relaciones intersemióticas tanto en el nivel descriptivo como del procesamiento.

\section{INFORME DE POLÍTICA MONETARIA (IPOM), UN GÉNERO PROFESIONAL IMPORTADO}

El género Informe de Política Monetaria (IPOM) pertenece al discurso de la economía y cumple con una doble función; por un lado, es leído en la formación de un economista y, por otro, establece las políticas macroeconómicas de un país y, por lo tanto, está vinculado a la práctica diaria de un profesional del ámbito de la economía. En este informe se dan a conocer las principales decisiones que toma el Consejo del Banco Central con el fin de velar por la estabilidad económica del país. El IPOM es marcadamente multimodal, ya que cada columna de su formato de diagramación, por lo general, alberga mayoritariamente un sistema semiótico de modo que los significados se construyen interrelacionadamente.

En específico, la problemática que representa la lectura de un género profesional en la formación de universitaria del ámbito de la economía es compleja, ya que estos géneros importados (Bolívar \& Parodi, 2015, Parodi, 2015) han sido trasladado a nuevos escenarios en una dimensión de 
conexión con el mundo académico. En específico, los géneros profesionales importados son fundamentales para la inserción laboral de los estudiantes (Hyland, 2004; Bach \& López, 2011). Al respecto, Cassany (2006) sostiene que un profesional, para poder insertarse en su área disciplinar, debe necesariamente conocer los géneros discursivos involucrados en su actividad profesional cotidiana, situación que no ocurre frecuentemente, ya que muchas veces los profesionales conocen los géneros discursivos solo en el momento de ingresar en el mundo laboral. Asimismo, Hyland (2004) sostienen que una comprensión exitosa de los textos de una disciplina se transforma en un camino fundamental de inserción en el ámbito disciplinar. Lo anterior no solamente porque, a través de los géneros profesionales, se logra obtener ciertos conocimientos especializados, sino porque implica también un rol importante en la integración de los individuos en sus comunidades discursivas (Swales, 1990, 2004).

Precisamente, una de las razones por la que se ha seleccionado el género IPOM radica en que se encontró en el contexto de circulación académico, en el marco del proyecto FONDECYT 1130033, lo que implica un reconocimiento a la necesidad de que sea leído por los estudiantes del área de la economía. Así también lo sostienen los docentes de esta área disciplinar al solicitar en diversas cátedras leer este género discursivo. Según especialistas de este ámbito, se requiere del dominio de este género por parte de los profesionales de la economía. En particular, según la bibliografía consultada, no existen estudios sobre la caracterización multimodal, sólo en el nivel retórico, del género IPOM en el discurso profesional especializado de la economía lo que lo convierte en un nicho a ocupar. En este sentido, Vásquez-Rocca (en prensa) ha descrito pormenorizadamente la organización retórica-funcional del género IPOM en el que se identificaron un total de 5 macromovidas, 13 movidas y 23 pasos que se detallan en la Tabla 1 . 
Tabla 1. Organización Retórico-Funcional del IPOM

\begin{tabular}{|c|}
\hline Macromovida 1. Preámbulo \\
\hline Movida 1.1. Organización de Contenidos \\
\hline Paso 1.1.1. Presentar de manera clasificada los contenidos del informe \\
\hline Movida1.2. Contextualización del informe \\
\hline Paso 1.2.1. Situar al lector \\
\hline Paso 1.2.2. Presentar contenidos del texto \\
\hline Paso 1.2.3. Informar aprobación de informe \\
\hline Macromovida 2. Síntesis \\
\hline Movida 2.1. Síntesis del estado del panorama mundial \\
\hline Paso 2.1.1. Justificar medida tomada por institución \\
\hline $\begin{array}{l}\text { Paso 2.1.2. Describir las principales causas y consecuencia en torno a un tema en } \\
\text { particular en un determinado contexto }\end{array}$ \\
\hline Paso 2.1.3. Declarar la proyección local de un tema específico \\
\hline Movida 2.2. Justificación de medidas \\
\hline Paso 2.2.1. Exponer los cambios esperados en un periodo de tiempo pasado. \\
\hline Paso 2.2.2. Argumentar una decisión de un periodo de tiempo pasado \\
\hline Macromovida 3. Contextualización \\
\hline Movida 3.1. Explicación y ejemplificación de conceptos \\
\hline Paso 3.1.1. Presentar un núcleo temático \\
\hline Paso 3.1.2. Explicar conceptos centrales que están vinculados al núcleo temático \\
\hline Paso 3.1.3. Ilustrar la relevancia del núcleo temático \\
\hline Movida 3.2. Proyección futuros escenarios \\
\hline Paso 3.2.1. Proyectar futuros escenarios \\
\hline Macromovida 4: Constatación y proyección \\
\hline Movida 4.1. Situar al lector \\
\hline Paso 4.1.1. Introducir al área temática \\
\hline Paso 4.1.2. Presentar los contenidos de la sección \\
\hline Movida 4.2. Panorámica de la situación actual y futura \\
\hline Paso 4.2.1. Evidenciar las causas y consecuencias vinculadas a un área temática. \\
\hline aso 4.22 Provectar una situación determinada del ámbito \\
\hline
\end{tabular}


Paso 4.2.3. Constatar una generalización de una o varias evidencias

Paso 4.2.4. Declarar compromiso

\section{Macromovida 5: Apoyo informativo}

Movida 5.1. Organización de artefactos

Paso 5.1.1. Presentar de manera clasificada los artefactos del informe

Movida 5.2. Definición de Términos

Paso 5.2.1. Definir términos utilizados en el informe

Paso 5.2.2. Descripción de siglas

Movida 5.3. Detalle de fuentes de información

Paso 5.3.1. Enlistar las referencias de fuentes de información

A partir de esta descripción, la autora sostiene que la macromovida 4 es la de mayor relevancia y constituye el eje central de este género, ya que en ella se ejecuta el propósito comunicativo del IPOM de proyectar, es decir, señalar qué ocurrirá con la economía a corto plazo (3 meses) y a largo plazo (2 años). Además, en esta macromovida, la manera de elaborar las proyecciones del IPOM está fuertemente anclado en los pasos 4.2.1. de "evidenciar", lo que quiere decir, la presentación de datos de diversa índole y 4.2.2. de "proyectar", afirmar de forma atenuada lo que ocurrirá en el futuro; dejando como pasos secundarios el 4.2.3. de "constatar" y 4.2.4. de "comprometer". Así, el paso de "evidenciar" (4.2.1.) y "proyectar" (4.2.2.) concentran la ejecución del propósito comunicativo.

\section{METODOLOGÍA}

El género IPOM, objeto de esta investigación, reviste importancia debido a que es producido originalmente en el mundo profesional, aunque fue recolectado en un contexto universitario educativo; lo que indica que actúa como un mecanismo articulador entre el mundo académico $\mathrm{y}$ el profesional. En este marco, el estudio tiene un enfoque cualitativo (Corbetta, 2007) de alcance descriptivo con un diseño no experimental y transeccional. El objetivo es describir el género IPOM del discurso de la economía a partir de una muestra de 45 textos en dos dimensiones complementarias, emitidos por el Banco Central entre los años 2000 y 2013. 
En cuanto al análisis, se consideran 2 dimensiones. La dimensión 1 busca identificar y cuantificar los "artefactos multisemióticos" que se presentan en el corpus del género IPOM de tal manera de categorizarlos bajo la propuesta de Parodi $(2010,2015)$. Para la identificación y cuantificación se siguieron los pasos metodológicos propuestos por Parodi (2010). En la dimensión 2, se buscó identificar las "relaciones intersemióticas" que existían entre el artefacto multisemiótico prototípico del IPOM y su cotexto verbal utilizando la propuesta metodológica de la RST. Cabe destacar que Mann y Thompson (1988) precisan que en el análisis se buscan las relaciones que representan juicios plausibles para el analista, por lo que son subjetivos, pero no por ello, menos científicos y, que además, para llevar a cabo el análisis, el texto es dividido en unidades. El tamaño de la unidad es arbitrario, sin embargo, tiene como principio fundamental representar lo que el autor quiere vincular. A esta unidad de análisis, la RST la denomina spam. La taxonomía de la RST divide las relaciones semánticas en dos grupos: multinuclear y núcleo-satélite. En el primero, diversos núcleos están conectados al mismo nivel, pero no hay dependencia; mientras que en el segundo, el Satélite aporta información adicional sobre el núcleo y, por lo tanto, sí existe dependencia. En el caso de las relaciones "núcleosatélite", se incluye una segunda división: relaciones de "contenido" y de "presentación". Las relaciones de "contenido" buscan establecer la unión que se da entre las partes del texto en el ámbito semántico. En el caso de las relaciones de "presentación", se focalizan en la relación entre las partes del texto, pero que además tiene algún efecto en el lector, es decir, presentan un foco pragmático (Mann \& Thompson, 1988). Aplicado el análisis se realizó un proceso de validación a través de la aplicación de un instrumento a 3 expertos en lingüística de nivel doctoral. Para la dimensión 1 se obtuvo un $95 \%$ de validación y un coeficiente de Kappa de 0,92 lo que según Landis y Kock (1977) es un acuerdo casi perfecto; para la dimensión 2 se obtuvo un $81 \%$ de validación y un coeficiente de Kappa de 0,70 lo que según Landis y Kock (1977) es un acuerdo considerable. Tras el análisis de cada dimensión, se realizó la integración de los datos, lo que permitió explorar las conexiones entre ambas a partir del estudio basado en corpus y una lectura situada. 


\section{RESULTADOS Y DISCUSIÓN}

En lo que sigue, se presentan los principales resultados del análisis. Para el caso de la dimensión 1, en el análisis del Corpus IPOM-2013 se identificaron un total de 3.983 artefactos y un promedio de 89 artefactos por IPOM, con una desviación estándar de 20,92. Estos datos estadísticos dan como resultado un coeficiente de variación de $23 \%$ lo que manifiesta una relativa homogeneidad en el periodo de 14 años analizados, ya que esto quiere decir que el $77 \%$ de los datos no presenta variación respecto del promedio. Además, se pudo observar que los "artefactos multisemióticos" utilizados para enseñar economía a los estudiantes en formación universitaria a través del género IPOM son cinco y principalmente el Gráfico $(77,4 \%)$ y la Tabla $(20,0 \%)$ y en menor medida el Complejo estadístico $(1,4 \%)$, la Fórmula $(1,2 \%)$ y el Esquema $(0,1 \%)$.

Butler (1993) sostiene que en los últimos 50 años los gráficos son más frecuentes que las figuras en la revistas científicas. Según Cleveland (1984), producto de este avance tecnológico significativo, los gráficos se han convertido en importantes medios de comunicación de información cuantitativa en la escritura científica. Al respecto, Tufte (1983) propone que de todos los métodos para analizar y comunicar información, los gráficos bien diseñados son los más simples $\mathrm{y}$, al mismo tiempo, los más poderosos instrumentos de información. De acuerdo a lo expuesto, la capacidad del "gráfico" de representar una gran cantidad de datos, los pone en primer lugar en la elección de los escritores del IPOM.

En términos de evolución diacrónica en el uso de artefactos, se ha mantenido a través de los años con cierta regularidad. Se destaca la incorporación del "complejo estadístico" en los últimos años, lo que evidencia un grado de complejización del uso prototípico de los gráficos. Ahora bien, si se revisan los resultados de otras investigaciones de uso de artefactos en géneros de la economía, el gráfico no es el más relevante en todos. En el caso de Gunnarsson (2009) que estudió el género artículo científico de la economía, el artefacto más relevante es la "tabla" más que los "gráficos". En tanto, Boudon y Parodi (2014) identifican y contabilizan los artefactos multisemióticos del género Manual de economía. En su análisis los autores identificaron la Fórmula como el artefacto predominante.

Resumiendo los resultados obtenidos de esta dimensión, se puede sostener que los gráficos son esenciales en el IPOM, tienen una regularidad 
diacrónicamente y aportan mayor objetividad a la construcción discursiva del IPOM.

En la dimensión 2 tras el análisis, se encontraron un total de 4.634 relaciones intersemióticas. Utilizando el software estadístico R versión 3.2.4. se pudo determinar que el promedio de "relaciones intersemióticas" por IPOM es de 103 relaciones, con una desviación estándar de 23,3 en la ocurrencia de tipos de relaciones intersemióticas en los 45 textos del género IPOM. Los datos anteriores dan como resultado un coeficiente de variación de $22 \%$ lo que evidencia un grado relativo de homogeneidad en los 14 años analizados. Esto quiere decir que hay un 22\% de variación de los datos con respecto a la media aritmética.

En cuanto al desglose por tipo de "relaciones intersemióticas", se determinó que un 3,3\% corresponden al tipo "núcleo-núcleo" y un 96,7\% a "núcleo-satélite". En el caso de las relaciones intersemióticas "núcleonúcleo", el 100\% de los datos evidencia una relación de tipo "unión", es decir, el autor ha conectado efectivamente ambos elementos (gráfico y cotexto verbal) a través de una marca explícita, pero no se observa otro tipo de conexión, como por ejemplo, elementos léxicos que se compartan en ambos segmentos (verbal y gráfico) ya sea verbos, sustantivos u otro tipo de rasgo. En cuanto a las relaciones "núcleo-satélite", en el Gráfico 1 se detallan los porcentajes de frecuencia relativa obtenidas en el análisis.

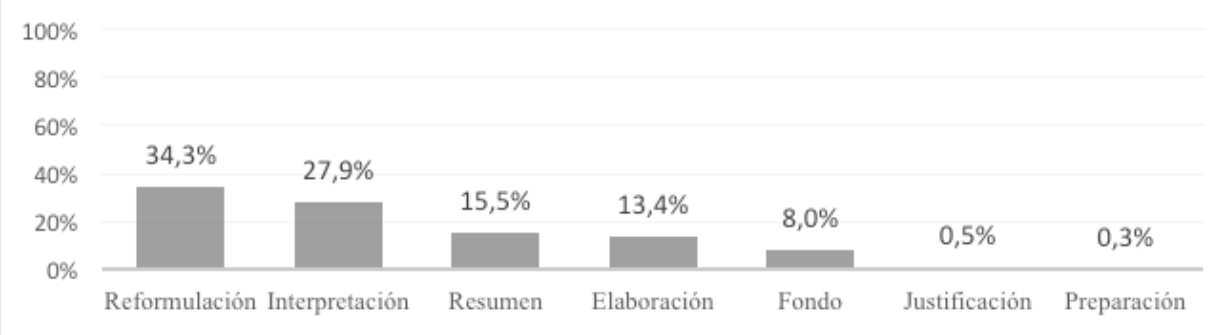

Gráfico 1. Tipos de relaciones intersemióticas Núcleo-Satélite.

La relación de "reformulación significa que, mayoritariamente, el núcleo es el "gráfico" que es reformulado en su totalidad por el cotexto verbal se trata de una relación de 1 a 1 , pero no siempre se incluye la totalidad de la información del núcleo. En cambio, en la "interpretación", 
el satélite, mayoritariamente el cotexto verbal, busca entregar evidencia o datos estadísticos que no están contenidos en el "gráfico2, pero que permiten explicar o ampliar la información de este, en definitiva interpretar los datos. Por tanto, en el cotexto verbal se presentan ideas no incluidas en el "gráfico". Por otro lado, se puede sostener que la "reformulación", en comparación con la relación de "interpretación", es una construcción más objetiva del discurso, esto basado en los planteamientos de Kebrat Orecchioni (1993) sobre los grados diversos de subjetividad que puede tener un autor en un texto, dependiendo del esfuerzo que realiza por borrar su huella del texto, o bien, de explicitar la fuente enunciativa de la afirmación. En este sentido, en la relación de Interpretación, más subjetiva, lo que se observa es que el sistema verbal busca entregar fundamentaciones y evidencias, que permitan ampliar y explicar la información contenida en el gráfico; por tanto, en el cotexto verbal se presentan ideas que no se pueden interpretar en el gráfico de modo de explicar por qué se producen los datos expuestos y por tanto, una mirada explícitamente identificada como sujeto enunciador, el Banco Central, claro que con altos grados de modalización. Una posible explicación al uso recurrente de estas relaciones surge a partir de la naturaleza mixta del discurso de la economía (McCloskey, 1985, Parodi \& Julio, 2015; Parodi, Julio \& Vásquez-Rocca, 2015), ya que en su búsqueda por hacer el discurso más cientificista, los autores del IPOM utilizan rasgos más asociados a las matemáticas -objetivos-, pero siguen utilizando recursos de las ciencias sociales, por ejemplo, en la interpretación de esos datos.

Otro hallazgo relevante en el uso de relación de Interpretación de la RST se puede explicar en mayor detalle con los planteamientos de Benveniste ([1977] 1999, 2014) en que señala que el sistema verbal es el único sistema con la capacidad de interpretarse a así mismo e interpretar a otros sistemas semióticos. Lo anterior concuerda con lo sostenido por Barthes (2014) en cuanto a la función de anclaje del sistema verbal, en que el sistema verbal es el guía para la interpretación de la imagen. Si bien Barthes (2014) estudia la imagen, sus planteamientos pueden ser extrapolados a otros artefactos, como por ejemplo al "gráfico". Así, el sistema verbal se posiciona como el único con la capacidad de interpretar. Esta capacidad interpretativa única del sistema verbal propone el desafío de repensar el análisis de las relaciones intersemióticas, ya que los sistemas no estarían al mismo nivel, si no que el sistema verbal siempre tendría un 
rol central.

\subsection{Análisis multidimensional}

Usando como eje el propósito comunicativo del texto de proyectar y su organización retórica ya descrita en trabajos anteriores (VásquezRocca, en prensa; Parodi, Julio \& Vásquez-Rocca, 2015) y, los resultados de la dimension 1 en que el "gráfic"o es el artefactos prototípico del IPOM y de la dimensión 2 en cuanto al tipo de "relaciones intersemióicas", a continuación se presenta la relación entre el "artefacto gráfico", "relaciones intersemióticas" y su ocurrencia en la organización retóricafuncional del género IPOM. Cabe señalar que a nivel de macromovidas, solo tres macromovidas presentan uso de "artefactos gráfico" y "relaciones intersemióticas" (macromovidas 2, 3 y 4). En el nivel de las movidas, la concentración se observa en la movida 2.1., en la movida 3.1. y en la movida 4.2.

En el nivel de pasos retóricos de la movida 2.1, el uso del "artefacto gráfico" y "relaciones intersemióticas" se presenta en el Gráfico 2. La concentración se produce en el "paso retórico 2.1.2." denominado Describir las principales causas y consecuencias en torno a la temática central.

2.1.1. Justificar medida tomada por 2.1.2. Describir causas y consecu institución

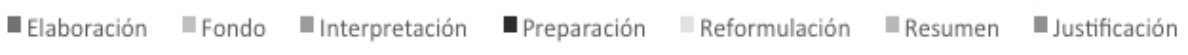

Gráfico 2. Relación entre pasos de movida 2.1., artefacto gráfico

y relaciones intersemióticas.

En cuanto a la movida 3.1. también se presenta una concentración del "artefacto gráfico" y de "relaciones intersemióticas" en un solo paso retórico, lo que se presenta en el Gráfico 3. 


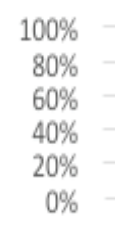

3.1.1. Presentar un núcleo temático

3.1.2. Explicar conceptos centrales

3.1.3. Ilustrar la relevancia del núcleo temático

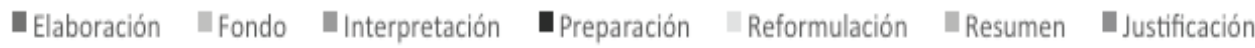

Gráfico 3. Relación entre pasos de movida 3.1., artefacto gráfico y relaciones intersemióticas.

Por último, como se observa en el Gráfico 4, en la movida 4.2. del IPOM no hay una concentración específica en un paso tanto en el "artefacto gráfico" como en las "relaciones intersemióticas". Se observa su uso en los pasos de "evidenciar" (4.2.1.) "proyecctar" (4.2.2.) y "constatar" (4.2.3.) medianamente equilibrada.

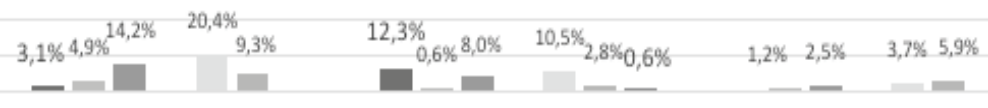

4.2.1. Evidenciar las causas y $\quad 4.2 .2$. Proyectar una situación consecuencias determinada

4.2.3. Constatar una generalización de una o varias

evidencias.

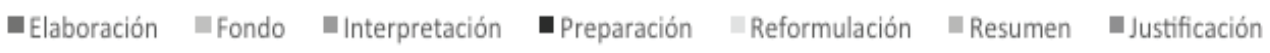

Gráfico 4. Relación entre pasos de movida 4.2, artefacto gráfico y relaciones intersemióticas.

Como se detalló existe un alto grado de concentración de uso del "gráfico" y de las "relaciones intersemióticas" en cinco pasos retóricos del IPOM. Esto evidencia que existen pasos retóricos que son 
eminentemente más multimodales que otros, pues la construcción del significado se realiza a partir de dos sistemas semióticos predominantes: verbal y gráfico-visual. Un aspecto importante a considerar en esta investigación es el rol que se ha relevado al "artefacto gráfico". Al ser "relaciones intersemióticas", la direccionalidad en que se produce la relación entre núcleo y satélite puede variar. Lo anterior quiere decir, que la dirección puede ir desde el gráfico al cotexto verbal, o bien, del cotexto verbal al gráfico. Ello no ocurre si solo se analiza el sistema verbal. Esta propuesta resulta ser un hallazgo relevante de la investigación, ya que en los estudios realizados con RST no se había planteado una esquematización al respecto, al menos hasta ahora. Por lo anterior, en la Tabla 2 se presenta la categorización que emergió en el análisis para el caso de la dirección núcleo-satélite.

\begin{tabular}{|l|l|}
\hline Dirección del vínculo & Descripción \\
\hline N-S & El gráfico funciona como núcleo y el cotexto verbal como satélite. \\
\hline S-N & El gráfico funciona como satélite y el cotexto verbal como núcleo. \\
\hline
\end{tabular}

En el IPOM y tal como se observa en el Gráfico 5, la direccionalidad de las relaciones del tipo "núcleo-satélite" presenta como unidad central al gráfico y como "satélite" al cotexto verbal (77\%). Al mismo tiempo, los datos permiten observar la direccionalidad en que el artefacto gráfico funciona en estos textos como Satélite y el sistema verbal como "núcleo" (solo en un $20 \%$ de los casos) y sólo un $3 \%$ en la relación "núcleo" a "núcleo".

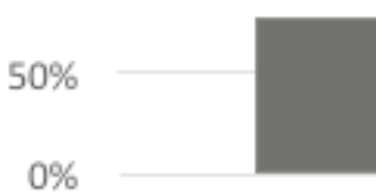

$\mathrm{N}-\mathrm{S}$

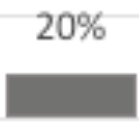

S-N
$3 \%$

$\mathrm{N}-\mathrm{N}$

Gráfico 5. Tipo de dirección de las relaciones intersemióticas del género IPOM. 
Estos resultados se pueden explicar a través de la capacidad que tiene el sistema verbal de ser el único sistema semiótico que puede cumplir la función de interpretante de otros sistemas semióticos (Benveniste, [1977] 1999, 2014). En particular, que el núcleo en las "relaciones intersemióticas sea preponderantemente el "gráfico" y el satélite, el "cotexto verbal" se da porque el "gráfico" no tiene esa capacidad de interpretación del sistema verbal. Ahora bien, en los casos en que el cotexto verbal funciona como núcleo, se observa que ocurre cuando el sistema verbal está interpretándose a sí mismo y el "gráfico" solo aporta un dato específico de esa explicación, pero el núcleo de lo que se quiere significar está dado por lo verbal. Como se ha dicho antes, Barthes (2014) también plantea esta idea que posiciona al sistema verbal en un rol de control de la interpretación de otros sistemas semióticos. El autor propone que "[...] el texto [sistema verbal en esta investigación] constituye realmente el derecho a la mirada del creador [...] sobre la imagen: el anclaje es un control [...]" (Barthers, 2014: 40). De esta manera, se identifica así la centralidad del "artefacto gráfico" en la construcción del significado en este tipo de género altamente especializado. El rol nuclear que tiene el "gráfico" en el IPOM, permite corroborar los planteamientos de Lemke (1998) y Parodi (2015) en cuanto a que cada disciplina determina la funcionalidad de sus artefactos multisemióticos y es donde adquieren su pleno sentido. Este hallazgo es una de las diferencias claves con los estudios anteriores realizando con RST en multimodalidad (Hiippala, 2012; Taboada \& Habel, 2013) y plantea un nuevo desafío para el estudio de los géneros con enfoque multimodal basado en corpus y considerando la disciplina.

\section{CONCLUSIONES}

Elobjetivoprincipal del estudio fue describirmultidimensionalmente el género IPOM a través de una metodología de enfoque cualitativo en la que las diferentes fases buscaron caracterizar el género desde dos dimensiones que posteriormente fueron analizadas de manera integrada. Ahora bien, en el escenario expuesto se puede concluir, en primer lugar, en cuanto al ámbito metodológico, que este estudio propone y realiza un análisis integral de un género discursivo, entregando no solo una visión lingüística tradicional (logocentrista), sino que incorporando, al mismo tiempo, dimensiones excasamente exploradas en el análisis de los géneros 
discursivos como es el caso de las "relaciones intersemióticas". En este sentido, uno de los aportes de esta investigación es que da cuenta de que los estudios de los géneros discursivos se enriquecen al ser abordados desde diferentes ángulos, pero integradamente, puesto que una panorámica integradora puede dar cuenta del fenómeno, abarcando todas sus complejidades. Ciertamente, aún falta integrar más dimensiones, pero el tipo de análisis propuesto en este estudio es un avance en la forma de estudiar los géneros discursivos.

En segundo lugar, a partir de la integración del análisis de las dimensiones, se evidencia que el "artefacto gráfico" funciona principalmente como núcleo y el cotexto verbal como satélite. Esto se explica por medio de la relación interpretante que propone Benveniste ([1977] 1999). El autor señala que el sistema verbal es el único que puede interpretar todos los otros sistemas semióticos, por tanto, si el "gráfico" tiene un rol central en este género, difícilmente las palabras podría funcionar como núcleo, ya que solo el sistema verbal tiene la capacidad de interpretar a otros. Esta visión es la que también ha discutido Barthes (2014), cuando propone la función de anclaje del las palabras para el caso de las imágenes. Según este último autor, toda imagen es polisémica, así se puede afirmar también que todo gráfico es polisémico, a todo Gráfico le subyacen una cadena flotante de significados que solo pueden ser anclados por el sistema verbal, es decir, el anclaje de los sentidos posibles del "gráfico". Así el escritor, obliga al lector a evitar unos significados y recibir otros a través de un dispatching, como lo denomina Barthes (2014), por lo tanto, esta elección dirige al lector a un significado escogido de antemano.

Lo anterior se traduce en que la construcción de significados en el género IPOM se sustenta a partir de las relaciones intersemióticas entre gráficos y cotexto verbal, en el que el gráfico actúa como núcleo en el 77\% de los casos y fundamentalmente por medio de relaciones intersemióticas de tipo "reformulación" e "interpretación"; esto quiere decir que leer textos del género IPOM es fundamentalmente construir representaciones mentales multisistemas semióticos de al menos dos códigos: uno gráfico visual y otro verbal. Basados en lo anterior y en una perspectiva multidimensional se puede sostener que leer textos del género IPOM requiere el desarrollo de una competencia multisemiótica en la que es imposible construir significados exclusivamente desde el sistema verbal.

Por último, con los hallazgos logrados en esta investigación se 
pretende contribuir a una mejor comprensión del género IPOM desde un punto de vista multidimensional. De la misma manera, este estudio ayuda al desarrollo de estrategias de lectura para los estudiantes que están en formación en economía y que deben leer este género importado. Así, esta investigación constituye un insumo para quienes están encargados de desarrollar estrategias de comprensión lectora para esta disciplina y para este género en particular.

En cuanto a las limitaciones, se reconocen dificultades principalmente en la dimensión 2, en la clasificación de las relaciones de las unidades de análisis y en la identificación de tales relaciones. Esta complejidad podría ser eliminada -en parte- en la medida que se efectúen más investigaciones en multimodalidad en el texto escrito utilizando la RST. Respecto de las proyecciones del estudio, se pueden señalar la posibilidad de ampliar el estudio hacia el ámbito experimental vinculando las relaciones intersemióticas y el procesamiento del texto, observando, por ejemplo, las rutas de lectura que se ejecutan en las relaciones de "reformulación" e "interpretación", puesto que este tipo de relaciones reflejan grados diferentes de subjetividad y, por tanto, se podría presuponer que en la relación de Interpretación podría predominar la lectura del sistema verbal a diferencia de lo que ocurriría en la de Reformulación. Esta propuesta plantea avanzar desde la descripción al procesamiento psicolingüístico.

\section{REFERENCIAS BIBLIOGRÁFICAS}

ALBALADEJO, T. (2012). "La semiosis en el discurso retórico. Relaciones intersemióticas y retórica cultural”. En Estética, Cultura Material e Diálogos Intersemióticos, A. Macedo, C. Mendes de Sousa \& V. Moura (eds.), 89-101. Braga: Centro de Estudios Humanísticos da Universidad do Minho.

ARISTÓTELES. (2003). Poética. Buenos Aires: Losada.

BACH, C. \& LÓPEZ, C. (2011). "De la academia a la profesión: Análisis y contraste de prácticas discursivas en contextos plurilingües y multiculturales". Cuadernos Comillas 1, 127-138.

BARTHES, R. (1977). "Rhetoric of the image". En Image, music and text, 
S. Headth (ed.), 32-51. Londres: Fontana.

(2014). Lo obvio y lo obtuso. Imágenes, gestos y voces. Madrid: Paidós. BATEMAN, J. (2014). Text and image. A critical introduction to the visual/ verbal divide. Nueva York: Routledge.

BENVENISTE, E. (1999). Problemas de lingüistica general II. México: Siglo XXI.

(2014). Últimas lecciones. Buenos Aires: Siglo XXI.

BOLÍVAR, A. \& PARODI, G. (2015). "Academic and professional discourse". En The Routledge Handbook of Hispanic Applied Linguistics, M. Lacorte (ed.), 459-476. Nueva York: Roudledge.

BOUDON, E. \& PARODI, G. (2014). "Artefactos multisemióticos y discurso académico de la Economía: Construcción de conocimientos en el género Manual”. Revista Signos 47 (85), 164-195.

BUTLER, D. (1993). “Graphs in psychology: Pictures, data, and especially concepts. Behavior research methods". Instruments \& Computers 25 (2), 81-92.

CANDLIN, C. (2014). "Afterword: Working with multimodality in action - conceptual challenges and interdisciplinary opportunities". Pedagogies: An International Journal 9 (1), 86-94.

CASSANY,D.(2006).Traslaslíneas.Sobrelalecturacontemporánea,http:// upvv.clavijero.edu.mx/cursos/ContenidosBasicosLenguaLiteratura/ vector 2/actividad7/documentos/TRASLASLINEAS.pdf[20/12/2016].

CLEVELAND, W. (1984). "Graphs in scientific publications". The American Statistician 38 (4), 261-269.

CORBETTA, P. (2007). Metodología y técnicas de investigación social. Madrid: Mc Graw Hill.

GLADIC, J. (2012). Niveles de comprensión y su relación con la predominancia de sistemas semióticos en textos del área de la lingüística: Una aproximación al fenómeno multimodal desde el discurso académico universitario. Tesis de magíster, Pontificia Universidad Católica de Valparaíso, Valparaíso, Chile.

GUNNARSSON, B. (2009). Professional discourse. Londres: Continuum. HALLIDAY, M. (1982). El lenguaje como semiótica social: La interpretación social del lenguaje y del significado. Ciudad de México: Fondo de Cultura Económica.

HIIPPALA, T. (2012). "The interface between rhetoric and layout in multimodal artefacts". Literary and linguistic computing 28 (3), 
461-471.

HYLAND, K. (2004). Disciplinary discourses. Social interactions in academic writing. Londres: Longman.

JEWITT, C. (2009). "Different approaches to multimodality". En The Routledge Handbook of Multimodal Analisys, C. Jewitt (ed.), 28-39. Londres: Routledge.

JEWITT, C, BEZERMAN, J, \& O'HALLORAN, K. (2016). Introducing Multimodality. Londres: Routledge.

KALTENBACHER, M. (2007). "Perspectivas en el análisis de la multimodalidad: Desde los inicios al estado del arte". Revista Latinoamericana de Estudios del Discurso 7 (1), 31-57.

KERBRAT ORECCHIONI, C. (1993). La enunciación. De la subjetividad en el lenguaje. Buenos Aires: Edicial.

KRESS, G. \& VAN LEEUWEN, T. (1996). Reading Images: The Grammar of Visual Design. Londres: Routledge.

LANDIS, J. \& KOCK, G. (1977). "The measurement of observeragreement for categorical data". Biometrics 33, 159-74.

LEMKE, J. (1998). "Multiplying meaning: Visual and verbal semiotics in scientific text”. En Reading science, J. Martin \& R. Veel (eds.), 87113. Londres: Routledge.

LIU, Y \& O’HALLORAN, K. (2009). “Intersemiotic Texture: Analyzing cohesive devices between language and images". Social Semiotics 19 (4), 367-388.

MANN, W. \& THOMPSON, S. (1988). "Rhetorical Structure Theory: Toward a functional theory of text organization". Text 8 (3), 243-281.

MARTINEC, R. \& SALWAY, A. (2005). "A system for image-text relations in wew (and old) Media". Visual communication 4 (3), 337-371.

MATTHIESSEN, C. (2009). "Multisemiosis and context-based register typology: Registerial variation in the complementarity of semiotic systems". En The world shown and the world told, E. Ventola \& A. Moya (eds.), 11-38. Oxford: Blackwell.

MAYER, R. (2001). Multimedia learning. New York: Cambridge University Press.

(2005). "Cognitive theory of multimedia learning". En The Cambridge Handbook of Multimedia Learning, R. Mayer (ed.), 3148. Cambridge: Cambridge University Press.

MCCLOSKEY, D. (1985). The Rhetoric of Economics. Wisconsin: 
University of Wisconsin Press.

NORRIS, S. (2014). "Developing multimodal (inter)action analysis: A personal account". En Interactions, images and texts, S. Norris \& C. Mauier (eds.), 13-17. Boston: Gruyter Mouton.

PAIVIO, A. (1979). Imagery and verbal processes. Hillsdale: Lawrence Erlbaum Associates.

(1986). Mental representations. A dual coding approach. New York: Oxford University Press.

(2007). Mind and its evolution: A dual coding theoretical approach. Mahwah, NJ: Erlbaum.

PARODI, G.; (2010). "Multisemiosis y lingüística de corpus: Artefactos (Multi)Semióticos en los textos de seis disciplinas en el corpus PUCV-2010". Revista RLA 48 (2), 33-70.

(2014). Comprensión de textos escritos. La teoría de la comunicabilidad. Buenos Aires: Eudeba.

(2015). "Más allá de las palabras: Exploración de rasgos multisemióticos en los textos de seis disciplinas en el Corpus PUCV2010". En Leer y escribir en contextos académicos y profesionales: Géneros, corpus y métodos, G. Parodi \& G. Burdiles (eds.), 291-334. Santiago: Ariel.

PARODI, G. \& JULIO, C. (2015). “Más allá de las palabras: ¿Puede comprenderse el género discursivo Informe de Política Monetaria desde un único sistema semiótico predominante?". Revista ALPHA 41, 133-158.

PARODI, G., JULIO, C. \& VÁSQUEZ-ROCCA, L. (2015). "Los géneros del Corpus PUCV-UCSC-2013 del discurso académico de la economía: El caso del Informe de Política Monetaria". Revista ALED 15 (3), 179-200.

ROYCE, T. (1999). Visual-verbal intnersemiotic complementarity in the Economist magazine. Tesis doctoral, The University of Reading, Centre for Applied Language Studies.

SADOSKI, M. \& PAIVIO, A. (2011). "Lexicons, contexts, events, and images: Commentary on Elman (2009) from the perspective of Dual Coding Theory". Cognitive Science 35, 198-209.

SAUSSURE, F. (1969). Curso de lingüistica general. Buenos Aires: Losada.

SCHNOTZ, W. (2005). “An Integrated Model of Text and Picture 
Comprehension". En The Cambridge Handbook of Multimedia Learning, R. Mayer (ed.), 49-69. New York: CUP. (2002). "Towards and integrated view of learning from text and visual displays". Educational Psychology Review 14 (1), 101-120.

SCHNOTZ, W. \& BANNERT, M. (2003). "Construction and interference in learning from multiple representation". Learning and Instruction $13,141-156$.

STÖCKL, H. (2004). "In between modes". En Perspectives on Multimodality, E. Ventola, Ch. Cassily \& M. Kaltenbacher (eds.), 9-30. Ámsterdam: Benjamins.

SWALES, J. (1990). Genre analysis. English in academic and research settings. Cambridge: Cambridge University Press. (2004). Research genres. Explorations and applications. Cambridge: Cambridge University Press.

TABOADA, M. \& MANN, W. (2006). "Applications of Rhetorical Structure Theory”. Discourse studies, 8(4), 567-588.

TABOADA, M. \& HABEL, C. (2013). "Rhetorical relations in multimodal documents". Discourse studies 15 (1), 65-89.

TUFTE, E. (1983). The visual display of quantitative information. Cheshire, CT: Graphics Press.

VASQUEZ-ROCCA, L. (en prensa). "Una aproximación lingüística al discurso de la economía a partir del género Informe de Política Monetaria".

Recibido el 17 de enero de 2017.

Aceptado el 2 de abril de 2017. 
